\title{
Left atrial size as a predictor for pulmonary hypertension in Ischemic Heart Disease
}

Khalid Kamal Hassan $^{(1)}$, Khalid Ahmed Emam El-Khashab ${ }^{(2)}$, Mohamed Gamal Mohamed $^{(3)}$ and Hassan Mohamed Ebied ${ }^{(4)}$

(1) Department of Cardiology, Faculty of Medicine, Fayoum University.

(2) Professor of Cardiology, Faculty of Medicine, Fayoum University.

(3) Lecturer of Cardiology, Faculty of Medicine, Fayoum University

(4) Lecturer of Cardiology, Faculty of Medicine, Fayoum University

Corresponding author: Khalid Kamal Hassan

E-mail address: khalidghallab2020@gmail.com

Tel:01000008971

\section{ABSTRACT}

BACKGROUND: Left atrial (LA) size reflects diastolic burden and was considered by many investigators to be a prognostic parameter of common cardiovascular death. However, the association between LA size and function and elevated pulmonary artery pressure in Ischemic Heart Disease (IHD) has not been well investigated. We hypothesized that LA size and function are associated with pulmonary hypertension (PH) in IHD. METHODS: Eighty patients with Coronary Artery Disease (CAD) were studied divided into two groups (ACS and chronic IHD). Twelve lead ECG was done to detect any abnormalities either LA enlargement, CAD or $\mathrm{PH}$. Transthoracic echocardiography (TTE) was done to assess LA dimensions, volume and function and assessment of
PASP. LA size was determined in three different methods; namely, LA volume index (LAV), LA area index, and LA dimension. LAV total emptying fraction was also determined. Pulsed Doppler E, A, E/A, tissue Doppler E', and E/E' were measured. Pulmonary artery systolic pressure (PASP) was estimated._RESULTS: All LA size parameters are significantly associated with $\mathrm{PH}$. LAV emptying fraction, E, E/A, and E/E' were also associated with $\mathrm{PH}$ significantly. CAD patients with $\mathrm{PH}$ showed larger LA size, higher E, E/A, and E/E' and lower LAV emptying fraction and $\mathrm{A}$ than CAD patients without $\mathrm{PH}$. CONCLUSION: LA size and function are related to $\mathrm{PH}$ in $\mathrm{CAD}$ patients. 
KEYWORDS: left atrial size,

left atrial function, pulmonary

hypertension, coronary artery disease. 


\section{INTRODUCTION}

The interest of the left atrium (LA) has resurged over the recent years. In the early 1980s, multiple studies were conducted to determine the normal values of LA size. Over the past decade, LA size as an imaging biomarker has been consistently shown to be a powerful predictor for outcomes, including major public health problems such as atrial fibrillation, heart failure, stroke, and death.(1) More recently, functional assessment of the LA has been shown to be a marker of cardiovascular outcomes and current available data suggest that the combined evaluation of LA size and function will augment prognostication.(2) Left atrial (LA) size reflects diastolic burden and is a prognostic parameter of common cardiovascular death. However, the association between LA size and function and pulmonary hypertension (PH) in Acute Coronary Syndrome (ACS) has not been well investigated.(3) Left atrial (LA) size has been identified as a predictor of heart failure and of survival in patients with cardiovascular and cerebrovascular diseases.(4)

Pulmonary hypertension (PH) is a relatively common finding in patients with coronary artery disease (CAD) and is usually associated with increased morbidity and mortality. (5)Although initial studies focused on patients with reduced left ventricular ejection fraction, more recent studies have shown left ventricular diastolic dysfunction is the most common cause of PH.(6)

On the other hand, Saraiva et al. showed that left atrial function had a significant correlation with right ventricular systolic pressure in chronic mitral regurgitation and that $\mathrm{PH}$ may not only depend on mitral regurgitation severity but also on LA function.(7) However, the association between LA size and function and $\mathrm{PH}$ in ACS has not been well investigated.

\section{PATIENTS AND METHODS}

This study is carried out to examine left atrial dimensions, volume and function in patients with ischemic 
heart disease and weather pulmonary hypertension is present or not.

This study include 80 patients of both sexes and different ages that had been selected from cardiology department FAYOUM UNIVERSITY HOSPITAL, who were put into two groups. Thirty patients, who were presented with acute coronary syndrome (ACS), are included in (Group II), compared with a control group of fifty patients diagnosed with chronic ischemic heart disease _chronic coronary syndrome (CCS)_ which are included in (Group I). Exclusion Criteria are Right ventricular infarction, chronic obstructive pulmonary disease, severe mitral regurgitation, mitral stenosis, and aortic stenosis, Chronic Hypertension and Atrial fibrillation. CCD patients satisfied one of the following inclusion criteria: history of myocardial infarction, angiographic evidence of $>50 \%$ stenosis in $\geq 1$ coronary vessels, evidence of exerciseinduced ischemia by treadmill or nuclear testing, history of coronary revascularization, or documented diagnosis of CAD by a cardiologist. The study design was approved by the hospital ethics committee, and all participants were provided written informed consent.

Both groups underwent ECG to detect ECG signs of left atrial abnormalities, CAD, and/or $\mathrm{PH}$, and transthoracic echocardiography using GE healthcare Vivid S5® (TTE) to assess left atrial size and function, and PH. Data documented with the ECG included $\mathrm{P}$ wave duration, amplitude and morphology, duration between $\mathrm{P}$ waves, ST segment deviation, $\mathrm{T}$ wave changes, pathological Q wave, and QRS duration and morphology, while data documented with TTE included LAEDVi by area length and modified Simpson's methods, LAESVi by arealength and modified Simpson's methods(8), LAEF by area-length method, E/A by transmitral flow, E/E' by tissue Doppler imaging, and pulmonary artery systolic pressure (PASP) by continuous wave Doppler (9). 


\section{STATISTICAL ANALYSIS:}

Calculations were done using with mean \pm SD and analyzed by commercially available statistical unpaired Student's t-test. A P-value of software (SPSS 17.0, SPSS Inc., less than 0.05 was considered to be

Chicago, IL, USA). Continuous significant(11).

variables were expressed as mean \pm standard deviation (SD). $\mathrm{PH}$ was defined as PASP>40 mmHg according to the current criteria(10). Each variable was tested for correlation with $\mathrm{PH}$ by univariate logistic regression analysis.

All variables with significant univariate association with $\mathrm{PH}$ were entered in a multivariate logistic regression analysis with $\mathrm{PH}$ as the dependent variable. The accuracy of different echocardiographic parameters for predicting PASP was assessed using a receiver operating characteristic (ROC) analysis. Continuous values were represented

\section{RESULTS}

Correlation between LAV by A-L method with Pulmonary Atrial Systolic Pressure among CCS group showed statistically significant positive correlation between PASP and LA volume with A-L index. Also, Correlation between LAV by A-L method with Pulmonary Atrial Systolic Pressure among ACS Group showed high statistically significant positive correlation between PASP and LA volume with AL- index.

Correlation between left atrial volume by Simpson's method with 
PASP among CCS group showed high statistically significant positive correlation between PASP and LAESV (Maximum LA volume) with Simpson's-index. Also, there was statistically significant positive correlation between PASP and LAEDV (Minimum LA volume) with Simpson's-index. Correlation between left atrial volume by Simpson's method with PASP among ACS Group showed high statistically significant positive correlation between PASP and LA volume with Simpson's index.

\section{DISCUSSION}

In our study, there was a significant prevalence concerning age. Nearly $90 \%$ of males and females of the two studied groups were over age 40, and this is in agreement with Rosamond et al. 2008 who reported that the Prevalence of CAD is highest in adults over age 35(12). In our study we found that patients with CCS (Group I) have an increase in all left atrial dimensions ; anteroposterior , mediolateral and superoinferior where patients presented with ACS (Group II) have relative increase in atrial dimensions and those with CCS have progressive increase in all dimensions (P.value < 0.001) and this result was not different than that found in patients $\mathrm{CAD}(13)$.

In our study, we found that LAV EF in patients of the two studied groups showed a strong and high significant negative correlation with LAVI either measured by A-L method or Simpson's method (P. value < 0.001). Measuring LAVI either with A-L method or Modified Simpson's method showed no significant differences in values, and this is in agreement with Lang et al. 2015 who reported that A-L and Simpson's methods is acquired for the assessment of LAVI(14).

In our study we found that patients with chronic IHD (group I) who have an increase in LAVI were associated with an increase in pulmonary artery systolic pressure yielding a high significant positive correlation between PASP and LAVI measured by A-L and Simpson's methods (P.value < 0.001). This result is in agreement with Miyata et al. 2012 who reported that LAV is associated with $\mathrm{PH}$ in $\mathrm{CAD}(15)$. 
Also, we found that patients who presented with ACS (Group II) showed a strong positive correlation between LAVI and PASP (P.value < 0.001). PH is thought to be caused by the increase of left atrial pressure and pulmonary wedge pressure. And not only systolic heart failure but also diastolic heart failure cause $\mathrm{PH}(16)$.

In our study we found that there is highly significant correlation between PASP and LA size, volume and function ( $\mathrm{P}$ value $<0.001)$ in the two studied groups. This result is in agreement with Miyata et al. 2012 who concluded that All LA size and functional parameters are significantly associated with $\mathrm{PH}$ in $\mathrm{CAD}(15)$.

\section{CONCLUSION}

LA size, volume and function are related to $\mathrm{PH}$, and are considered a good and robust prognostic tool for predicting $\mathrm{PH}$ in Ischemic Heart disease. 


\section{References:}

1. Møller JE, Hillis GS, Oh JK, Seward JB, Reeder GS, Wright RS, et al. Left atrial volume: A powerful predictor of survival after acute myocardial infarction. Circulation. 2003;107(17):2207-12.

2. Garcia MJ. Left Ventricular Filling. 2008;4:47-56.

3. Tsang TSM, Abhayaratna WP, Barnes ME, Miyasaka Y, Gersh BJ, Bailey KR, et al. Prediction of cardiovascular outcomes with left atrial size: Is volume superior to area or diameter? J Am Coll Cardiol. 2006;47(5):1018-23.

4. Abhayaratna WP, Seward JB, Appleton CP, Douglas PS, Oh JK, Tajik AJ, et al. Left Atrial Size. Physiologic Determinants and Clinical Applications. J Am Coll Cardiol. 2006;47(12):2357-63.

5. Simonneau G, Gatzoulis MA, Adatia I, Celermajer D, Denton C, Ghofrani A, et al. Updated clinical classification of pulmonary hypertension. J Am
Coll Cardiol. 2013;62(25

SUPPL.).

6. Rosenkranz S, Gibbs JSR, Wachter R, De Marco T, VonkNoordegraaf A, Vachiéry J-L. Left ventricular heart failure and pulmonary hypertension. Eur Heart J [Internet]. 2016; ehv512. Available from: http://eurheartj.oxfordjournals.o rg/lookup/doi/10.1093/eurheartj/ ehv512

7. Sarvari SI, Haugaa KH, Stokke TM, Ansari HZ, Leren IS, Hegbom F, et al. Strain echocardiographic assessment of left atrial function predicts recurrence of atrial fibrillation. Eur Heart J Cardiovasc Imaging. 2016;17(6):660-7.

8. Kip KE, Hollabaugh K, Marroquin OC, Williams DO. The Problem With Composite End Points in Cardiovascular Studies. The Story of Major Adverse Cardiac Events and Percutaneous Coronary Intervention. J Am Coll Cardiol. 2008;51(7):701-7.

9. Modi K, Soos MP, Mahajan K. 
Stent Thrombosis. In Treasure

Island (FL); 2020.

10. Milani R V., Lavie CJ, Rubiano

A. Clinical correlates and

reference intervals for

pulmonary artery systolic

pressure among

echocardiographically normal

subjects. Circulation.

2002;106(5):2797-803.

11. Cutlip DE, Nakazawa G,

Krucoff MW, Vorpahl M,

Mehran R, Finn A V., et al.

Autopsy validation study of the

academic research consortium

stent thrombosis definition.

JACC Cardiovasc Interv

[Internet]. 2011;4(5):554-9.

Available from:

http://dx.doi.org/10.1016/j.jcin.2

011.01 .011

12. Rosamond W, Flegal K, Furie

K, Go A, Greenlund K, Haase

$\mathrm{N}$, et al. Heart Disease and

Stroke Statistics - 2008 Update

A Report From the American

Heart Association Statistics

Committee and. 2008;8721(71).

13. Pritchett AM, Jacobsen SJ, Mahoney DW, Rodeheffer RJ,
Bailey KR, Redfield MM. Left

atrial volume as an index of left

atrial size: A population-based

study. J Am Coll Cardiol.

2003;41(6):1036-43.

14. Lang RM, Badano LP, Mor-Avi

V, Afilalo J, Armstrong A,

Ernande L, et al.

Recommendations for cardiac

chamber quantification by

echocardiography in adults: An

update from the American

society of echocardiography and

the European association of

cardiovascular imaging. Eur

Heart J Cardiovasc Imaging

[Internet]. 2015;16(3):233-71.

Available from:

http://dx.doi.org/10.1016/j.echo.

2014.10.003

15. Miyata-Fukuoka Y, Izumo M,

Shimada Y, Kuwahara E,

Gurudevan S V., Tolstrup K, et

al. Left atrial size and function

are related to pulmonary

hypertension in coronary artery

disease. Echocardiography.

2012;29(5):535-40.

16. Lam CSP, Roger VL,

Rodeheffer RJ, Borlaug BA, 
Enders FT, Redfield MM.

Pulmonary Hypertension in

Heart Failure With Preserved

Ejection Fraction. A

Community-Based Study. J Am

Coll Cardiol [Internet].

2009;53(13):1119-26. Available

from:

http://dx.doi.org/10.1016/j.jacc.

2008.11.051 


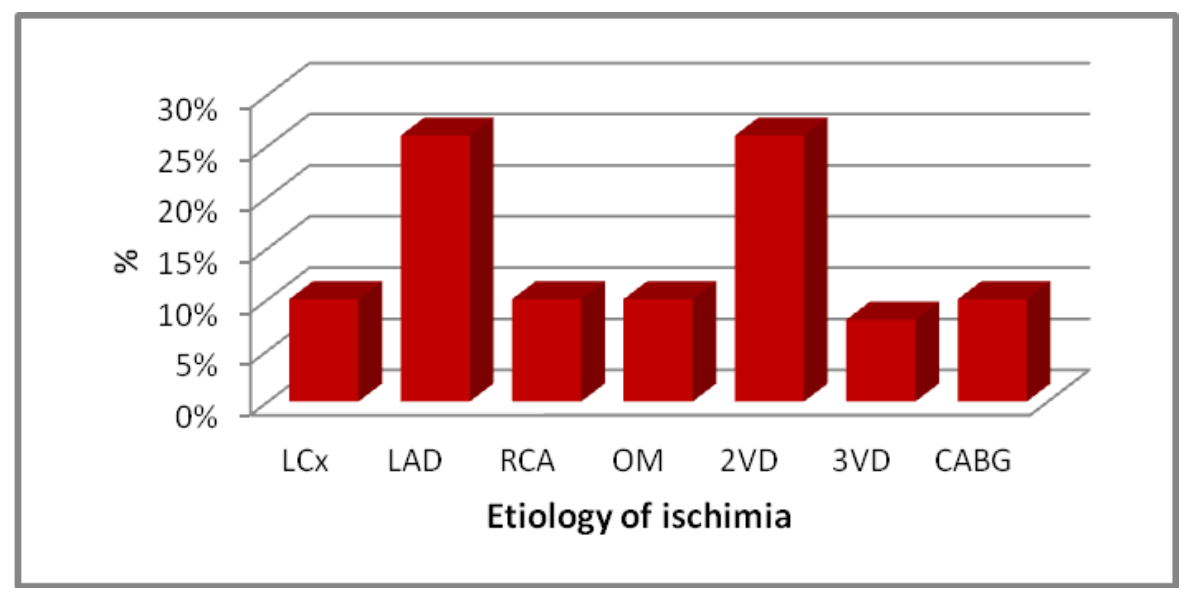

Figure 1: Comparison of etiology of Ischemia percentage in group I (CCS).

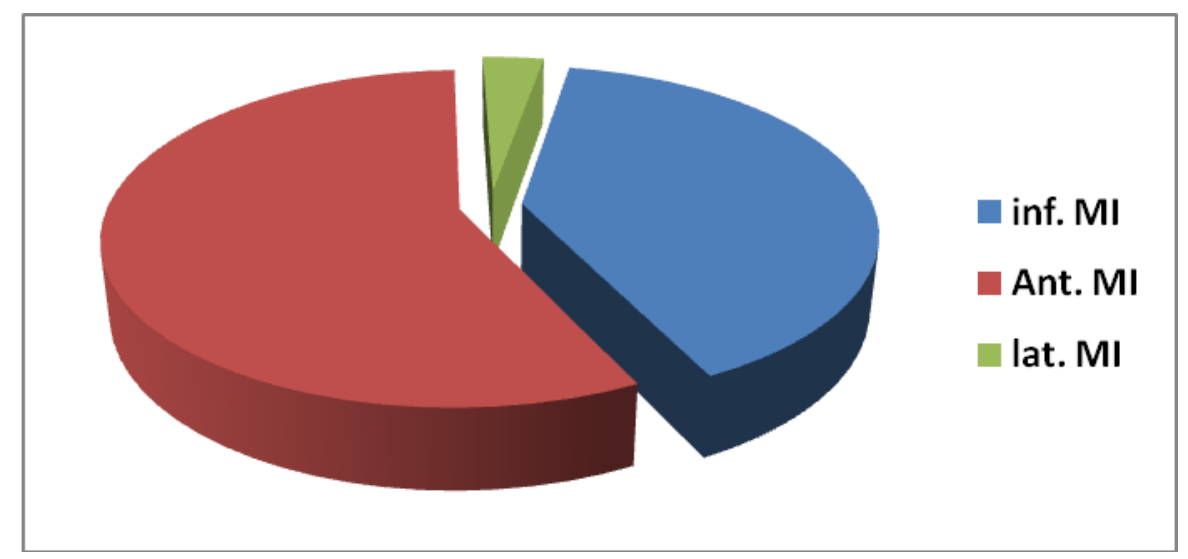

Figure 2: Comparison of Site of infarction percentage in group II (ACS). 
Table 1: Comparison of left atrium Volume among different study groups by Modified Simpson's Method:

\begin{tabular}{|c|c|c|}
\hline \multicolumn{2}{|c|}{ Study Groups } & \multirow{3}{*}{$\begin{array}{l}\text { LA Volume } \\
\text { Modified Simpson's } \\
\text { Method }\end{array}$} \\
\hline $\begin{array}{c}\text { Group II } \\
(\mathbf{n}=30)\end{array}$ & $\begin{array}{c}\text { Group I } \\
(\mathrm{N}=50)\end{array}$ & \\
\hline Mean \pm SD & Mean \pm SD & \\
\hline $33.5 \pm 12$ & $33 \pm 17.8$ & LAEDV \\
\hline $60.3 \pm 16.2$ & $62.5 \pm 21.5$ & LAESV \\
\hline $17.8 \pm 6.1$ & $17.4 \pm 8.8$ & LAEDV Indexed \\
\hline $32.1 \pm 7.9$ & $33.6 \pm 10.2$ & LAESV indexed \\
\hline $44.6 \pm 7.5$ & $48.5 \pm 13.4$ & LAV EF (\%) \\
\hline
\end{tabular}

Table 2: Comparison of left atrium Function among different study groups by Tissue Doppler:

\begin{tabular}{|c|c|c|}
\hline \multicolumn{2}{|c|}{ Study Groups } & \multirow{2}{*}{ Tissue Doppler } \\
\cline { 1 - 2 } $\begin{array}{c}\text { Group II } \\
(\mathrm{n}=30)\end{array}$ & $\begin{array}{c}\text { Group I } \\
(\mathrm{N}=50)\end{array}$ & \\
\hline Mean \pm SD & Mean \pm SD & \multirow{2}{*}{$\mathbf{E}^{\prime}\left(\mathbf{c m} / \mathbf{s e c}^{\prime}\right)$} \\
\hline $\mathbf{8 . 5} \pm \mathbf{1 . 9}$ & $\mathbf{8 . 6} \pm 2.0$ & E/E' \\
\hline $8.4 \pm 3.5$ & $\mathbf{7 . 9} \pm 3.1$ & \\
\hline
\end{tabular}

Table 3: Comparison of Pulmonary Atrial Systolic Pressure and Left Ventricular ejection fraction among different study groups:

\begin{tabular}{|c|c|}
\hline \multicolumn{2}{|c|}{ Study Groups } \\
\hline $\begin{array}{c}\text { Group II } \\
(\mathrm{n}=30)\end{array}$ & $\begin{array}{c}\text { Group I } \\
(\mathrm{N}=50)\end{array}$ \\
\hline Mean \pm SD & Mean \pm SD \\
\hline
\end{tabular}




\begin{tabular}{|c|c|c|}
\hline $36 \pm 10$ & $34 \pm 9$ & PASP (mmHg) \\
\hline $54 \pm 8$ & $54 \pm 7$ & LV EF (\%) \\
\hline
\end{tabular}


Table 4: Correlation between LAV by A-L method with Pulmonary Atrial Systolic Pressure among group I "CCS":

\begin{tabular}{|c|c|c|l|}
\hline Sig & P-value & PASP & \multicolumn{1}{|c|}{ LAV (A-L) } \\
\hline HS & $<0.001$ & 0.336 & LAEDV \\
\hline HS & $<0.001$ & $0.417^{*}$ & LAESV \\
\hline HS & $<0.001$ & 0.332 & LAEDV(Index) \\
\hline HS & $<0.001$ & 0.408 & LAESV (Index) \\
\hline
\end{tabular}

Table 5: Correlation between left atrial volume by Simpson's method with PASP among group I "CCS":

\begin{tabular}{|c|c|c|l|}
\hline Sig & P-value & PASP & LAV (Simpson) \\
\hline S & $<0.05$ & 0.353 & LAEDV \\
\hline $\mathrm{HS}$ & $<0.001$ & 0.424 & LAESV \\
\hline $\mathrm{S}$ & $<0.05$ & 0.345 & LAEDV(Index) \\
\hline $\mathrm{HS}$ & $<0.001$ & 0.417 & LAESV (Index) \\
\hline
\end{tabular}

Table 6: Correlation between LAV by A-L method with Pulmonary Atrial Systolic Pressure among Group II "ACS":

\begin{tabular}{|c|c|c|l|}
\hline Sig & P-value & PASP & \multicolumn{1}{|c|}{ LAV (A-L) } \\
\hline HS & $<0.001$ & 0.686 & LAEDV \\
\hline HS & $<0.001$ & 0.600 & LAESV \\
\hline HS & $<0.001$ & 0.694 & LAEDV(Index) \\
\hline
\end{tabular}




\begin{tabular}{|l|l|l|l|}
\hline HS & $<0.001$ & 0.620 & LAESV (Index) \\
\hline
\end{tabular}

Table 7: Correlation between left atrial volume by Simpson's method with PASP among Group II "ACS":

\begin{tabular}{|l|c|c|l|}
\hline Sig & P-value & PASP & LAV(Simpson) \\
\hline HS & $<0.001$ & 0.685 & LAEDV \\
\hline HS & $<0.001$ & 0.586 & LAESV \\
\hline HS & $<0.001$ & 0.692 & LAEDV(Index) \\
\hline HS & $<0.001$ & 0.611 & LAESV(Index) \\
\hline
\end{tabular}

